Session 3257

\title{
The Oklahoma State University Experience in Teaching Engineering Design and Drafting at the Freshman Level
}

\author{
Dr. John W. Nazemetz, Dr. John B. Solie, Dr. David R. Thompson \\ Oklahoma State University
}

Introduction. This paper is intended to convey the process by which a freshman level course in design and drafting was developed at Oklahoma State University and the experiences and lessons learned during the first three years of the course. The course was developed to present the engineering design process by instructing students in the concepts and procedures used in engineering design and then exposing them to the entire design process by requiring student teams to conceptualize, develop, analyze, document (CAD drawings and report), and test a prototype physical device which is to solve a specific problem under time and cost constraints. This course, which provides students with an early, hands-on, thorough design experience, provides a venue for assessing the impact of an early design experience on students.

Background The convergence of several independent events in the early 1990's led to the development of an expanded course in Engineering Design and Drafting. These events included a College decision to move to centralized computer facilities to replace and expand those which had been developed and were being maintained by the individual Schools of Engineering. As Oklahoma State University's Engineering College operates on a professional school concept, this computer development strategy resulted in a focus on the computing needs of upper-class students. While freshman and sophomore computing labs existed, much of the software was distributed among the various departments; the individual departments had limited budgets and the breadth of software requirements resulted in each department purchasing minimum numbers of copies of software that were used for only a portion of the year (i.e. only for certain classes). Thus, many Schools found that their students were frustrated by the limited number of software copies in the home departments while the same software had been purchased by other departments and was being used at different times of the year but was not available for use by students outside the departments. Several sharing arrangements developed between departments but these were somewhat haphazard and awkward to administer. In order to address the problems with utilization and maintenance, a scheme for centralization of hardware, software, and maintenance was developed. This centralization was administered by the College and its goal was to provide the computer capacity (hardware and software) to support the computing requirements of all students at all levels. The funding source for these resources was a student technology fee which was implemented and collected at the University level.

At the same time, the College initiated a study of its freshman drafting course. The course was a one hour manual drafting course. The course focused primarily on sketching (isometric and oblique), lettering, and multiview (2-D) drawing of mechanical parts. The committee reviewing the course represented the various departments of the College and developed a number of objectives for the course after reviewing the literature available. The members of the committee were charged with developing a course that would meet the basic drafting needs of the various Schools of Engineering and, at the same time, introduce the student to the 
engineering design process. The course, to be implemented at the freshman level, was to meet a number of diverse objectives developed from a number of different viewpoints. These objectives included:

Introduce the Student to the Design Process

Provide a Hands-on Design Experience

Use the Course to Excite Students and Improve Retention

Provide a Basis for Understanding the Role and Use of the Engineering Sciences in

Design

Develop a Beginning Competence in the Use of CAD

Develop a Comprehension and Compliance with Accepted Drafting Practice

Develop an Appreciation of the Role of Drafting in Each Engineering Discipline

Provide a Design Team Experience to the Students

Develop Design Documentation and Reporting Skills and Experience

Demonstrate the Role of the "Foundation Courses" (Math, Chemistry, Physics, Etc.) in the Design Process

Provide a Common Design Experience that Subsequent Courses Could Build Upon

Provide a Design Experience that Would Improve the Students' Performance in Capstone Design Courses

Provide the Student with Experience in Solving Open-Ended Problems

Introduce the Student to the Ethical Considerations in Design

Assisting the Student in making Career Decisions

The committee developed a possible course syllabus based upon a two credit hour course that would hold a one hour lecture and a two hour lab each week. Key concepts for the course included the design and construction and physical display (testing) of the solution to a semester long design project. Of the fifteen weeks of instruction, nine lectures and eight labs focused upon CAD and the remaining classes (five lectures, seven labs and a midterm) were used in pursuit of the design project. The faculty assigned to teach the class were to meet the spirit of the committees intentions but were allowed to modify the skeleton syllabus.

Instructor Philosophies. The two faculty assigned to teach the course undertook the detailed course design with four guiding philosophies:

1) that the design experience should follow a structured, theoretically-based design procedure,

2) that the design project should be realistic: open ended, have a large number of possible solutions, require some introductory level engineering analysis and testing to find the best alternatives, consider cost of the solution in the process, and have a realistic probability that the student team's design might not satisfy all of the design goal(s),

3) that all documentation (CAD drawings, design notebooks, and design reports) should be completed in a professional manner, and

4) that the students should be exposed to the realism of having others construct their designs from their documentation.

The first philosophy was based upon the desire of the instructors to minimize the time and effort of the students by leading them through an academically rigorous sequence of problem definition, structured brainstorming and alternative generation (using morphological charts), quantitative and physical analysis and testing of the alternative concepts, selection of the preferred alternative, documentation of the design (drawings, bill of materials, estimated cost, and construction instructions), oversight of the construction of the design by other students (while they constructed the other team's design), and physical testing of the completed device. It was felt that this approach to the design experience would provide effective, self-actualized learning experiences 
that were often not encountered until after graduation. The instructors stressed analysis over "cut and try" methods of solution. The instructors discouraged students accepting their first idea and then simply tinkering with it, encouraging the economy of the development of alternative concepts and evaluation of the competing concepts through simple engineering and economic analyses prior to committing large amounts of resources to the design. By having the student teams exchange designs and not constructing their own designs and by using a semi-formal system for incorporating engineering design changes, the instructors hoped to definitively demonstrate the importance of clear documentation and communication and the problems associated with the release of incomplete design packages and/or making major modifications to the design after release.

Laboratory Development Two support laboratories had to be designed and constructed to support this course. The laboratories were sized to accommodate twenty one students in each section. The CAD laboratory is a dedicated lab (CAD only) and consists of twenty three (the twenty-one students, the instructor, and one spare) 486 IBM compatible DOS computers with CADKEY 7 installed which are networked to two H-P Laserjet printers. The laboratory also contains an A-D size plotter. CADKEY 7 is also installed on $40^{+}$other 486 computers in the open (non-dedicated computer areas maintained by the College. These facilities are open from 8:00 a.m. through 2:00 a.m. throughout the semester; the open area includes two additional B-D size plotters. The instructor's computer is equipped with a LED overhead display which projects the instructor's computer screen display onto a nine foot screen. The fabrication laboratory is set up with eleven work stations (5'x2.5' tables), eleven sets of common hand tools, and a complement of light machines. The machines include bandsaws(2), sanders(2), drill presses(2), a table saw, a scroll saw, and a lathe. In addition to the common hand tools, a set of lab supplied materials (balsa, wire, solder, etc.), spare parts, measuring tools, specialty saws, hammers, and other common handtools are also maintained in the lab. These labs are open from 6:00 p.m. 11:00 p.m.; students may also work in lab during any of the scheduled lab periods ( 22 hours/week) during the design testing and fabrication portions of the course.

Semester Plan The semester plan integrates the lecture and lab materials in three segments. The segment introduces the student to the design process, hand drawing of multiview and pictorial drawings, and development of a 2-D and 3-D CAD drawing capability. At the completion of this segment, the student can draw 3-D wireframes and use CADKEY's layout mode to develop fully detailed and dimensioned drawings of both individual mechanical parts and, using level/layers, organize assemblies of parts and develop individual detailed and dimensioned drawing sets. In the second segment, alternative concepts for solution of the semester's design project are developed and the engineering analysis of example solutions are presented. This part of the course culminates in the student team's completion of their design release package, documenting the design concept they wish to be built. During the final segment, lecture material presents 3-D solid modeling and the use of 3-D solid, 3-D wireframe, and 2-D models in engineering analysis and the use of graphics in the various engineering disciplines. The laboratory sessions are devoted to the fabrication of the students' designs. The solids modeling and analysis software of CADKEY as well as examples from CNC Machining (MASTERCAM) are presented.

Student Materials Based upon the limited lecture and laboratory time available in the course, the instructors developed and published (at cost) a course supplement. The supplement provides students with copies of the overheads (with space for notes) presented during lecture and lab. The copies of the overheads to facilitate class preparation, note taking, and review. The supplemental readings, focus on engineering analyses, and as well as provide supplemental materials such as lists of available tools and materials, project scheduling aids, 
motor performance data, example drawings, engineering calculations, homework assignments, and grading sheets. The table of contents of the course supplement is shown below:

Course Outline (Syllabus, Schedule, Attendance Policy, Policy on) Academic Dishonesty, Course Objectives/Expectations)

Lecture 1 Introduction to Course

Lecture 2 Introduction to Computer Aided Drafting with CADKEY

Lecture 3 Datum Usage and Communicating the Design through Dimensioning

Lecture 4 3-D Wireframes in CADKEY

Lecture 5 Engineering Design Process and Introduction to Design Project

Lecture 6 Major Considerations in the Design Project

Lecture 7 Quantitative Analysis of the Design I

Lecture 8 Quantitative Analysis of the Design II

Lecture 9 Construction Techniques

Lecture 10 Design Evaluation and Revision

Lecture 11 Solids Modeling

Lecture 12 Using the 3-D Model in Further Analyses

Lecture 13 Role of Graphics and Design in Engineering Disciplines

Lecture 14 Design Approaches

Laboratory 1 DOS File Manipulation, CADKEY Files, and Hand Sketching

Laboratory 2 CADKEY Commands

Laboratory 3 Building to Specifications

Laboratory 4 Dimensioning in CADKEY

Laboratory 5 3-D Wireframe Drawing and Morphological Charting of Alternatives

Laboratory 6 Layout and Design of Investigative Experiments

Laboratory 7 Entity Transformation/Rotation and Experimentation

Laboratory 8 Analysis and Refinement of Design Concept Design Package Preparation I

Laboratory 9 Design Release Package Preparation II

Laboratory 10 Design Release Package Preparation III

Laboratory 11 Design Release Package Critique and Device Construction I

Laboratory 12 Device Construction II

Laboratory 13 Device Construction III

Laboratory 14 Device Testing and Final Revision

Laboratory 15 Laboratory Section Competitions

Assignment 1 Hand Sketching 1 - Orthographic Projections P2 Paper for Assignment 1

Assignment 2a Hand Sketching 2 - Isometric and Oblique

P2 and P3 Paper for Assignment 2

Assignment 2b First CADKEY Drawing

Assignment 3 2-D CADKEY Drawings

Assignment 4 2-D Dimensioned Drawings

Assignment 5a 3-D Wireframe Drawings

Assignment 5b Morphological Charts and Sketches of Preliminary Concepts for Device Morphological Chart Forms
Assignment 6a 3-D, Fully Dimensioned, Multiview Drawings

Assignment 6b Sketch of Team's Concept for Device

Assignment $6 \mathrm{c}$ Planned Experiments to Investigate Concept Planned Experiment Form

Assignment 7a Entity Translation and Rotation and Development of Exploded Assemblies

Assignment 7b Overall Project Schedule Project Schedule Forms

Assignment 8a Part 1 of Design Package

Assignment 8b Preliminary Wireframe Model of Team Design Concept

Assignment 8c Bill of Materials and Weight Estimate Bill of Material Form

Assignment 9 Part 2 of Design Package

Assignment 10 Design Release Package Design Release Package Grading Sheet

Assignment 11a Design Release Package Peer Evaluation Design Phase Peer Evaluation Form

Assignment 11b Component Completion

Assignment 11c Evaluation of Design Release Package by Construction Team

Evaluation of Design Release Form

Assignment 12 Subassembly Completion

Assignment 13 Prototype Completion

Assignment 14a Completed Device

Assignment 14b Design Notebook Design Notebook Grading Sheet

Assignment 14c Peer Evaluation of Construction Team Members Construction Peer Evaluation Form

Take Home Portion of Final Exam

Grading Sheet for Take Home Portion of Final Exam

\section{Appendices}

A.1 A Program for Success in Academia

A.2 Where to Get Help

A.3 Questions that You Shouldn't Ask ...

B.1 CADKEY Screen Layout

B.2 CADKEY Menu System (Where to Find the Commands)

B.3 CADKEY Immediate Mode Command List

B.4 CADKEY Status Window Options

C Design Project Overview

D. Wireframe Drawing Strategy Examples

E. Using CADKEY's Layout Mode

F. Design Analysis Computations

F.1 Supplemental Motor Performance Data

F.2 Sample Calculations

G. Engineering Change Request Forms

H. Form to Accompany Late (Excused) Homework Submission

I. Technical Report Writing Guidelines

Instruction Lectures in the course are delivered by the faculty in charge and the laboratory instruction and supervision is the responsibility of the teaching assistants. 
Design Projects The design projects are modified each semester. These generally have required the student teams to design solutions to move devices and or materials over particular distances and obstacles. In each semester, there were a number of competition categories in which the students could choose to compete. The competition categories typically involved different propulsion options such as size of motor used, or evaluation criterion such as time to complete activity or amount of load carried in a specific time. The projects have involved:

a) Efficiently moving styrofoam balls the length of an eighty foot track which was composed of ten eight foot sections $\left(20^{\circ}\right.$ concrete downslope, sand, tar, astroturf, masonite, masonite, astroturf, tar, sand, and a $20^{\circ}$ concrete upslope). Competition categories were either speed (lowest elapsed time to move a minimum of three balls), load (maximum number of balls moved), or combination (number of balls in the least time). The evaluation criteria were:
Score $=$ Cost of Device $(\$) *$ Elapsed Time $(\mathrm{sec})$
(speed category - low score wins))
Score $=$ Number of Balls/Cost of Device
Score $=$ Number of Balls $/[$ Cost $*$ Elapsed Time $]$
(load category - high score wins)
(combination cat. - high score wins)

b) Efficiently moving a device the length of a fifty-six foot track sections $\left(20^{\circ}\right.$ concrete downslope, astroturf, gravel, an arched plywood bridge, three inch deep water, sand, and a $20^{\circ}$ concrete upslope) in the least time. The competition categories involved which of three types of DC motors were used. The evaluation criteria were:

Score $=$ Elapsed Time $*$ Cost of Device

(low score wins in each motor class)

c) Efficiently moving a load the length of a fifty-six foot track sections $\left(20^{\circ}\right.$ concrete downslope, astroturf, gravel, an arched plywood bridge, three inch deep water, sand, and a $20^{\circ}$ concrete upslope) in the least time. The competition categories involved how the water hazard was negotiated (leapt, float, or run along the bottom)

Score $=$ Weight $*$ Distance Moved/Cost of Device (high score wins in each negotiation class)

d) Efficiently traverse a twenty six foot track $\left(20^{\circ}\right.$ concrete downslope, astroturf, masonite, and a horizontal to vertical ramp \{five foot rise in ten foot length approximating a $100 \%$ power curve \}). The device could start on the flat portion of the track or on the upslope starting ramp There were four propulsion choices (three motors and gravity) but only one competition category. The evaluation criteria were:

Score $=($ Height on ending ramp - Starting Height $) *(7 /$ Wattage of Motor(s) Used $) *$ (\$50.00/Cost of Device)

(high score wins)

Experiences/Observations A number of observations on the teaching of engineering students initial engineering design experience are apparent from the five semesters of experience with this course. They are:

Need for Physical Device Construction and Testing as Part of the Design Experience. The need for a physical "day of reckoning" cannot be understated. Many, if not most of the current students do not possess a strong comprehension of the physical meaning of the fundamental forces and principles which underlie engineering design. They simply do not have a "feel" for what the analysis numbers mean. They are weak in development and analysis of alternative concepts of possible solutions. In all design competitions, over half of the student designs failed to perform the design task, usually due to oversight of a fundamental physical concept (i.e., conservation of energy, friction losses, or structural strength) even after having been shown the calculations that predict these design shortcomings. The poor performance of the students' designs is a very valuable lesson 
as the students learn that what seems to be a good idea must be subjected to objective engineering analysis to uncover and correct design flaws prior to construction. They learn that they must be broad in their search for alternatives in the design stage as the rigor of this phase of the design process determines the performance and cost of their solution. They begin to realize the large number of possible solutions that exist to each problem when they observe that each of the seventy or more teams in the class has a different device configuration and that the performance of these devices varies greatly.

Students Are Frustrated By The Design Process Which Is Fundamentally Different From Their Previous Approach To Problem Solving Almost all of the students in the class have been trained by our educational system to believe that there is a straight line step by step linear method of solution to all problems and that all problems have a single solution. Most students initially believe the design process (define problem, develop alternatives, analyze alternatives, select best solution, implement), also implies a nice, linear progression to a solution. The students feel that they have failed if they must step back and repeat a step because the currently pursued alternative is inadequate. It is difficult to instill in them that "going back to the drawing board" is a common step in the design process as more information and experiences become available. Students tend to react in one of three ways as they pursue a weak solution alternative - a) ignore all data that indicates the alternative is weak and doggedly pursue the original alternative, b) blame the instructor or other external entity for the problem and absolve themselves of responsibility for the problem, or c) recognize that they have a problem and realize that additional development and consideration of alternatives and/or analysis could have avoided the problem and will use this experience in their next design experience. It is, obviously, this third reaction that is sought in the course and the one that is of the greatest benefit to the student in his/her future career.

Frustrated Students Need Care And Interventions As the design process is, to the new engineering student, a new solution methodology and way of thinking, they are often frustrated when the paradigm of the past fails them. The students often fail to realize that it is the introduction of a new paradigm, rather than some personal inadequacy, is the root of the problem. If the student conceives that he/she is to blame they will either feel that they are ill suited for engineering as a career or shift the blame to the instructors and/or course. If they engage in either of these behaviors, it is detrimental to their self esteem, confidence, and/or performance. Immediate and frequent instruction and feedback that focuses on the root of the problem is vital to the students' long term success. When frustrated, students will allow small problems to serve as reasons for withholding their efforts. For example, highly frustrated students let any perceived or actual failure of the Instructor or Teaching Assistants to serve as a excuse to withhold their efforts while less frustrated students do not perceive the same occurrences to be a hindrance at all. The key seems to be to reduce frustration of the students through individual intervention. This requires training of the Teaching Assistants and Instructors to be sensitive to this issue and confront it rather that allowing frustration to build. It is also important that the students understand what is happening and have them develop their own strategies for dealing with it.

A Large Number Of The Concepts Being Taught In The Course Require The Student To Experience Them Rather Than Study Them The course strives to convey a large number of experiences that the student can learn from and build upon as he/she pursues his/her career as well as technical information that will not be presented in any other courses. Succeeding courses rely upon the assumption that this material has been mastered. The course is intended to provide a common 
experience upon which the succeeding courses in the curriculum can build. The large number of experiences in the course each require that the student execute a series of actions (or inactions) that provides the experience. All of these require time and an effort on the part of the student and instructor and result in a relatively high workload. This is especially true because the course must allow students to make some missteps (which are inherent in the design process) and then correct the mistakes and assess how to avoid or more quickly recognize the misstep in the future. Students consistently rate the workload high in course evaluations and it is noteworthy that they suggest an increase in credit hours and not a reduction in content or coverage.

Issues and Assessment of Strategies for Addressing these Issues A number of observations and strategies for dealing with the problems and issues in the course have evolved and include:

Course Coverage The topics and hands-on experiences in the course provide an effective introductory and common design experience as well as developing basic drafting skills. Due to the synergy and mutually dependent nature of design activities, it is imperative that the course develop fundamental drafting skills, an academic understanding of the design process and take the student through a complete design experience that results in a physical demonstration of a prototype of the design concept selected. The course outline is regarded as the minimum spanning set of activities to achieve this. The course provides a complete, common design experience to the students, but testing has shown that it develops only a somewhat superficial capability in drafting and adherence to drafting standards due to the time limitations in the course.

Workload and Load Assignments The workload in the course is substantial for both students and instructors. While the current course is two semester credit hours, both the students and instructors feel that three credit hours is a more appropriate and, perhaps, the minimum number of hours that should be dedicated to this vital first experience in design. With more than 200 students enrolled, a half time assignment should be allowed for the instructor. Each teaching assistant should also be half time, teaching two laboratory sessions. One quarter time teaching assistant should be employed to maintain the laboratories and the grading spreadsheets. The students workload is generally related to the complexity of the design that they develop. While simplicity of design is stressed, most students do not have an experiential basis for determining if their concept is "too complex" and it is difficult to dissuade them from a complex design. It is only after spending a large amount of time and comparing their design those of other students do they begin to understand the impact of complexity on the workload. No universal solution to this problem has been found. Presentation of simple, workable designs during the design phase of the course has not been effective in dealing with this problem.

Assuring Consistency in the Course Consistency in grading and material presentation in essential in any multi-section course. Adequate procedures and training are the keys to achieving this goal. Currently, this is the only course in the College that requires all teaching assistants to undergo three days of training prior to the start of the course. This training focuses on material to be covered as well as how to best convey the material and how to react to students' problems as well as how and when to intervene in the student's and the design teams' activities. This training is supplemented by weekly $11 / 2$ hour sessions reviewing the material to be covered and scoring/grading of homework. The grading of the course normalizes grades between the various instructors to remove grading bias (e.g. one instructor grades harder than another). While all inconsistencies have not been eliminated, 
without this training and grading adjustment, it is felt that the achievement of course goals would be compromised. Each semester, the instructor also teaches one laboratory section to assure that they are experiencing the same problems as the teaching assistants in the same timeframe.

Developing Communication Skills. Having the each student team exchange their design release package with another for construction is very effective in demonstrating the problems that result from unclear and inadequate documentation. This provides an understanding of the problem, but since only one report is developed in the course, the impact is difficult to assess. Anecdotal information from instructors of succeeding courses is mixed with regard to the impact on communication skills. Students seems to take peer evaluation of inadequacies to heart much more than instructor evaluations. Whether this is due to their experience with another team's package is unknown.

Developing Engineering Analysis Skills The development of basic assessment skills improved substantially from the start to the end of the course. Student develop an understanding of how engineering analysis improves the probability of successful designs and their ability to comprehend the physical meaning of the numbers is improved.

Reducing Student Frustration As both drafting and the design process are new to the student and it is likely that frustration will occur, the teaching assistants maintain all of their "office hours" in the CAD and fabrication laboratories. This provides an opportunity to answer students' questions in a timely manner. The teaching assistants supervise and assist in laboratory 6:00 to 11:00 p.m. Sunday through Thursday. Students appreciate the presence of the teaching assistants, but many of the students use the assistants to answer their questions rather than preparing (reading and studying) prior to coming to laboratory. This does compromise the retention of material and is inefficient. Students who pursue this strategy also are typically impatient (presumably because they have no other option for proceeding) if the teaching assistant is not immediately available and consume a large amount of the teaching assistants time in the lab. No solution to this problem has been developed; students do not react well when they are instructed to prepare before coming to lab.

Cumulative Nature of Material Many students found that the course moved too fast for them or felt that material that they did not comprehend could be learned at a later time. As the knowledge is cumulative (dependent on prior material), students who fall behind generally are unable to catch up and drop the course. Increased efforts to intervene by the teaching assistants have been ineffective.

Working in Teams In this course, many students face team work for the first time. In order to instill accountability, each team member evaluates the performance of the other team members. The performance of each team member is observed by the instructors to the extent possible and the team's grade is distributed based on individual contribution. The individual grades are distributed based on the instructors' observations and the peer input and the grades given within a team is such that the average of the individual grades equal the grade on the team effort (i.e. if the report is a $\mathrm{B}$, the three team members could get $\mathrm{B} / \mathrm{B} / \mathrm{B}$ or $\mathrm{A} / \mathrm{B} / \mathrm{C}$ or $\mathrm{A} / \mathrm{C} / \mathrm{C}$, etc.) This effectively deals with the requirement for all team members to contribute to the project.

Overall Conclusions Overall, it can be concluded that freshman can do well in the course and benefit from the experiences that it provides. Input from a self assessment paper that each student writes at the end of the semester indicates that the students are realizing the lessons contained in the course. 